\title{
Superordinate and Subgroup Identification as Predictors of Intergroup Evaluation in Common Ingroup Contexts
}

\author{
Catriona H. Stone \\ University of Exeter

\section{Richard J. Crisp} \\ University of Kent
}

\begin{abstract}
We examined the combined effects of subgroup and superordinate group identification on intergroup evaluations within common ingroup identity contexts. In Studies 1 and 2 we observed a positive correlation between subgroup identification and intergroup bias, and a negative correlation between superordinate identification and bias. In Study 3 we replicated these effects using alternative measures and observed a common path underlying these relationships: the perceived psychological distance between the self and outgroup. In Studies 4 and 5 we replicated this path model and found that the relationship between superordinate identification and intergroup bias was contingent upon making the superordinate identity salient, but this was not the case for subgroup identification. We discuss the findings in the context of theoretical and applied development of the Common Ingroup Identity Model.
\end{abstract}

KEYWORDS common ingroup identity, distinctiveness threat, identification

THE social categorization approach to intergroup conflict asserts that weakening the salience of intergroup distinctions can reduce intergroup bias, and this basic idea underpins several key models of conflict resolution. One of the most prominent approaches, the Common Ingroup Identity Model (Gaertner \& Dovidio, 2000), has shown much potential in reducing intergroup conflict. Subsequent work has found that in some contexts, however, the link between category salience and the reduction in intergroup bias is not so straightforward. In particular, different people may respond to a common ingroup identity in different ways, and motivational factors may determine whether an individual reacts favorably or negatively to such changes in category representation. Previous work has

\footnotetext{
$\overline{\text { Author's note }}$

Address correspondence to C. H. Stone, 89

Valence Road, Lewes, East Sussex, BN 7255,

UK [email: c.h.stone@gmail.com] or to

R. J. Crisp at the Department of Psychology,

University of Kent, Canterbury, Kent,

CT2 7NR, UK

[email: r.crisp@kent.ac.uk]
} 
established that subgroup identification may exert a moderating effect on the relationship between categorization and bias in common ingroup contexts (e.g. Crisp, Stone, \& Hall, 2006; van Leeuwen, van Knippenberg, \& Ellemers, 2003). However, there has as yet been little work on the effects of identification with the superordinategroup. In this article, we tested the hypothesis that both subgroup and superordinate group identification are critical in understanding the social impact of recategorization and common ingroup identities.

\section{The Common Ingroup Identity Model}

The Common Ingroup Identity Model (CIIM) (Gaertner \& Dovidio, 2000; Gaertner, Dovidio, Anastasio, Bachman, \& Rust, 1993) advocates the elimination of intergroup boundaries by increasing the salience of an existing common ingroup identity, or introducing factors which facilitate the recategorization of two subgroups into an inclusive identity (see Self-Categorization Theory for an account of the proposed processes: Oakes, 1987; Turner, Hogg, Oakes, Reicher, \& Wetherell, 1987).

Laboratory and field research has yielded support for the effectiveness of this technique in reducing subgroup conflict. Factors such as cooperation (e.g. Gaertner, et al., 1999; Gaertner, Mann, Dovidio, Murrell, \& Pomare, 1990; Gaertner, Rust, Dovidio, Bachman, \& Anastasio, 1994), perceptual cues such as similar dress (e.g. Dovidio, Gaertner, Isen, \& Lowrance, 1995), contact between groups of equal status (Gaertner et al., 1994), institutional norms (Gaertner et al., 1994), positive mood (Dovidio et al., 1995), shared ingroup/outgroup threat, and taking the perspective of outgroup members (Dovidio et al., 2004) can all create common ingroup identities that include former outgroup members. It is also now well established that an observed increase in positive attitudes toward the outgroup in such contexts is mediated by a shift in the perceiver's cognitive representation of the intergroup context from two groups into one inclusive category (e.g. Gaertner et al., 1990). Despite the wealth of evidence supportive of the idea that common ingroup categorization can reduce intergroup bias, some recent work has found that in some contexts recategorization may not reduce and can even increase intergroup bias. Theorists have interpreted these divergent effects as suggestive of motivational processes operating in such contexts (e.g. Hornsey \& Hogg, $2000 \mathrm{c}$ ). We outline these processes below.

\section{Social identity and subgroup distinctiveness}

Social Identity Theory (SIT) (Tajfel \& Turner, 1986) argues that group members have a motivated drive to acquire distinctiveness for their ingroup from the outgroup. Central to SIT is the notion that the evaluation of oneself is partly achieved in terms of the social groups to which perceivers belong. Because one's self-esteem is derived from group memberships (e.g. Crocker \& Luhtanen, 1990) it follows that the attainment of a positive self-evaluation rests upon the ability of individuals to positively differentiate the ingroup from relevant outgroups. A key aspect of this theory is that in order to derive a sense of positive self-esteem from ingroup membership, the ingroup must be viewed as being distinct from other groups (Mlicki \& Ellemers, 1996). Distinctive social categorization also clarifies and defines social contexts, reducing uncertainty, and providing a set of prescriptive ingroup norms to guide perceivers' behavior (Hogg, 2000, 2001). According to SIT then, distinctiveness is highly valued by group members, and they will strive to protect it. There is much evidence in favor of this notion that in conditions that compromise distinctiveness, ingroup favoritism is used as a way of re-attaining positive distinctiveness from the outgroup (Brown \& Abrams, 1986; Tajfel, 1982; Turner, Brown, \& Tajfel, 1979). There is, however, one important caveat to this argument. Not all group members will be motivated to achieve, maintain, and protect ingroup distinctivenesspeople will vary in the extent to which such goals are important to them. 


\section{Identification and subgroup distinctiveness}

In order for the above reactive processes to occur, perceivers must be highly committed to their ingroup. If one does not regard a particular identity as central to their self-definition, they are unlikely to use it as a source of self-esteem (Branscombe, Wann, Noel, \& Coleman, 1993). Work carried out by Jetten, Spears, and Manstead (1996, 2001; see also Roccas \& Schwartz, 1993) has examined the reactions of individuals that attach little, or much, importance to social categories under conditions of threatened group distinctiveness. Using similarity of group norms as the distinctiveness manipulation, it was found that intergroup similarity (i.e. same group norms) increased bias for individuals highly committed to the ingroup (high identifiers) compared to those not committed to the ingroup (low identifiers; Jetten et al., 2001, Study 2). Other research has used psychological distance between groups as the manipulation of intergroup distinctiveness. Jetten et al. (2001, Study 1) dichotomized high and low identifiers, and manipulated distinctiveness by varying the distribution of group scores following a bogus task, to provide conditions of low distinctiveness and high distinctiveness. In line with predictions, there was no difference in bias between high and low identifiers in the high distinctiveness condition. However, in the low distinctiveness condition, high identifiers displayed significantly higher levels of stereotypic differentiation compared to low identifiers. Overall, this research indicates that when a similar outgroup impinges upon ingroup distinctiveness, high identifiers will exhibit elevated levels of intergroup bias, whereas bias will be attenuated for low identifiers (see Jetten \& Spears, 2003; Spears, Jetten, \& Scheepers, 2002 for reviews, and Jetten, Spears, \& Postmes, 2004, for a meta-analysis). This idea is critically important for literature on conflict reduction, since in the same way that a highly similar outgroup can threaten distinctiveness, so too can the imposition of a superordinate categorization.

\section{Distinctiveness, identification and common ingroup identity contexts}

The creation of a common ingroup identity requires that individuals will give up existing subgroup identities and take on a new inclusive identity (van Knippenberg \& van Leeuwen, 2001). Ingroup identification should thus moderate the effectiveness of a recategorization (Jetten \& Spears, 2003, p. 234). Given their lower investment in the ingroup, lower subgroup identifiers should be relatively willing to take on board the common ingroup identity, leading to reductions in ingroup favoritism consistent with the CIIM. However, a different pattern may be expected for higher identifiers. Because higher identifiers define and evaluate themselves to a large extent in terms of that group membership, they should be most motivated to defend the distinctiveness and way of life of the ingroup. The merging of the ingroup and outgroup implied by recategorization should therefore result in a reactive increase in bias, in line with the ideas outlined by SIT above (for a discussion of the integration of SIT and models of bias reduction, see Crisp \& Beck, 2005). There is indeed evidence that subgroup identification does moderate responses to recategorization in line with this model. Hornsey and Hogg (2000a) observed increased ingroup favoritism when a superordinate university identity was made, in relative terms, more salient than subgroup faculty identities. They argue that the heightened bias following superordinate categorization was due to a motivated increase in differentiation caused by threatened ingroup distinctiveness. Crisp et al. (2006, Study 4) went on to establish, in a similar context, that these comparatively high levels of bias observed in the superordinate university identity condition were driven specifically by high faculty (subgroup) identifiers.

While it is now clear that subgroup identification can moderate the effects of making a superordinate category salient, little work has been directed toward a second possible moderator in common ingroup contexts-identification with the common ingroup itself. Because 
recategorization entails a shift from one identity to another, the loss of one's subgroup would be particularly striking if there is no or very little identification with the superordinate category. In this research, we therefore aimed to extend recent work into motivational processes involved in common ingroup contexts by examining not only the effects of subgroup identification, but simultaneously, the moderating role of identification with the superordinate group membership.

\section{Identification at multiple levels of inclusiveness}

Some recent literature has begun to examine the link between superordinate identification, subgroup identification, and intergroup bias. In the procedural justice domain, Huo, Smith, and colleagues' research suggests that commitment only to subgroup identities can have potentially aversive consequences for subgroup relations. However, high attachment to superordinate identities might furnish more harmonious intergroup relations despite simultaneous high attachment to the subgroup (Huo, Smith, Tyler, \& Lind, 1996). Similarly, in their study of a shipyard workforce, Lipponen, Helkama, and Juslin (2003) found that while subgroup identification was positively related to subgroup bias, superordinate identification was negatively correlated with subgroup bias. Finally, Bizman and Yinon (2001) looked at subgroup (Israeli) identification, superordinate (Jewish) identification, perceived realistic threat (competition for valued resources), and intergroup bias. They found that higher identification with the Jewish superordinate identity led to lower bias, whereas higher identification with the Israeli subgroup led to increased bias toward Russian Jews (the minority immigrant outgroup). This work suggests a further important caveat to the involvement of identification in common ingroup contexts. Although high subgroup identification may lead to superordinate identities being perceived as threatening (and so lead to increased ingroup favoritism), simultaneously, higher identification with the superordinate group can lead to less bias and a greater willingness to accept the merging of the ingroup and outgroup. ${ }^{1}$

\section{This research}

We aimed to extend the research reviewed above in several important ways. We build on preliminary studies that have examined both subgroup and superordinate group identification in a new context: national and supranational identities. More importantly, however, we tested a path model of the dual effects of subgroup and superordinate group identification on intergroup bias via psychological distance with the outgroup (Studies 3 to 5). We predicted that subgroup bias will be positively correlated with subgroup identification in common identity contexts but that subgroup bias will be negatively correlated with superordinate group identification, and that both will be mediated by psychological closeness with the outgroup. Because we were interested specifically in the combined effects ${ }^{2}$ of subgroup and superordinate group identification under conditions of threat (to ingroup distinctiveness), in Studies 1 to 3 we made a recategorized European identity salient for all participants. Then in Study 4, we assessed the effects on pre-and post-recategorization intersubgroup bias and finally in Study 5 we tested these assumptions in a between-subjects design.

\section{Study 1}

In Study 1 we aimed to provide an initial test of the sub- and superordinate identification model. The target ingroup was 'British', the target outgroup 'French', and 'Europe' was the superordinate group. We predicted that when a shared European (superordinate) identity was made salient, British (subgroup) identification would be positively correlated with bias toward the French, while European (superordinate) identification would be negatively correlated with intergroup bias.

\section{Method}

Participants and design Eighty-five British undergraduate students (46 males and 30 females, ${ }^{3}$ 
mean age $=20$ ) participated in return for a small monetary payment.

Procedure Participants were informed that the questionnaire was concerned with national attitudes. The first section measured British identification followed by European identification, using four items (adapted from Jetten, Branscombe, Spears, \& McKimmie, 2003, and Luhtanen \& Crocker, 1992); 'I identify strongly with other British people', 'Being a British person is an important part of who I am', 'I feel strong ties with other British people', and 'I feel a sense of solidarity with other British people' $(\alpha=.927)$. These items were modified to measure European identification, e.g. 'I identify strongly with other Europeans' $(\alpha=.932)$. Responses on all measures in all studies were anchored from 1 (not at all) to 9 (very much) unless otherwise stated.

In the second section, the concept of European integration was made salient, thus invoking the notion of a common ingroup identity. This was achieved by presenting participants with the following paragraph:

We are interested in your opinions toward what some may say is an inescapable merging of Britain into a 'United States of Europe'. Some argue that being 'British' is no longer a meaningful way to describe oneself in a time of closer European integration. Rather, British people should abandon any outdated notions of their special status and instead classify themselves as simply 'European'.

Participants were informed that the research was concerned with 'how national groups work together to solve generic problems that require creativity, intelligence, initiative, and motivation'. They were also told that 'in this particular survey, we are examining peoples' opinions concerning British and French work groups'. Participants then completed measures of ingroup and outgroup evaluation.

Dependent measures Participants completed measures of inter-subgroup evaluation used in previous research on the CIIM (adapted from Hornsey \& Hogg, 2000c). The two items per group were: 'I'd feel good about working within a mainly British team' and 'How strongly would you prefer the leader of an ideal team to be British?' $(r(85)=.419, p<.001)$. These items were reworded to measure French evaluation $(r(85)=.405, p<.001)$. In both cases the two items were averaged to form a single measure of ingroup and outgroup evaluation. Intergroup bias was calculated by subtracting outgroup evaluation from ingroup evaluation.

\section{Results and discussion}

Intergroup bias We regressed intergroup bias onto British and European identification. The analysis revealed that subgroup and superordinate identification both significantly predicted bias, with subgroup identification being positively related to bias $(\beta=.43, p<.001)$ and superordinate group identification being negatively related to bias $(\beta=-.39, p<.001)$. On entering an interaction term into the multiple regression on a second step, there was no superordinate identification $\times$ subordinate identification interaction $(\beta=-.144, p=.728)$.

We further regressed ingroup evaluation onto British and European identification. Increasing levels of British identification were associated with higher ingroup evaluation $(\beta=.491$, $p<.005)$, whereas there was no association between European identification and evaluation of the ingroup $(\beta=-.084, p=.439)$. We also regressed outgroup evaluation onto British and European identification. Here, we observed no relationship between British identification and outgroup evaluation $(\beta=-.041, p=.705)$. However, European identification was positively associated with outgroup evaluation $(\beta=.492$, $p<.005) .^{4}$

The positive correlation between subgroup identification and bias is in line with previous research: following recategorization, the higher the level of subgroup identification, the higher the level of intergroup bias (see Crisp \& Beck, 2005; Crisp et al. 2006; van Leeuwen et al., 2003). However, we found a negative correlation between commitment to the shared European identity and bias. For our British participants then, those who highly identified with being British were more biased against the French after reading a paragraph designed to prime the European superordinate identity. However, 
simultaneously, those participants who highly identified with being European were less biased against the French after reading a paragraph priming their European identity. These findings illustrate the importance of studying both subgroup and superordinate level identification for predicting intergroup bias in common ingroup contexts.

\section{Study 2}

One could argue that our manipulation of superordinate group (European) salience in Study 1 carried some element of value threat (i.e. it did not only imply a loss of distinctiveness, but also that the recategorization had other negative connotations). We felt that the manipulation we chose was appropriate to the context we studied, while at the same time presenting no significant problem for conceptual clarity. It has high face validity because typically, British views toward European integration are invariably laced not only with issues of distinctiveness, but also of evaluation. For example, there is much literature documenting the skepticism of the British toward the EU and European integration (e.g. Medrano, 2003; Rutland \& Cinnirella, 2000). More importantly, however, previous research has established that this manipulation has identical effects to less elaborate means of making a superordinate identity salient. In particular, Crisp et al. (2006) directly compared this manipulation with a simpler version (a single superordinate category label) and found both to have identical effects on evaluations as a function of identification. Similarly, Crisp \& Beck (2005) have shown that simple manipulations of similarity (e.g. listing five characteristics that the ingroup and outgroup have in common) also exert the same effects on evaluations as a function of identification as do manipulations that employ the more elaborate method used here. However, to establish that this manipulation would have the same effects as a more basic distinctiveness threat manipulation, Study 2 was carried out using a more basic manipulation of recategorization.

\section{Method}

Participants and design Fifty-seven British undergraduate students ( 8 males and 49 females, mean age $=20$ ) participated in return for a small monetary payment.

Procedure The procedure was identical to that of Study 1, with the exception of a different manipulation of common ingroup identity salience and alternative dependent measures. Participants were presented with a list of continents, and were simply asked to identify from which they came; Africa, Antarctica, Asia, Europe, Oceania, North America, or South America (see Hornsey \& Hogg, 2000b, 2000c, for similarly subtle manipulations). The British and European identification scales were reliable and so were therefore averaged to form single indices ( $\alpha \mathrm{s}=.926$ and .955 respectively).

Dependent measures Measures of bias were administered using a scale partially adapted from Wright, Aron, McLaughlin-Volpe, and Ropp (1997). Participants were asked to indicate how they felt about both the British and French on dimensions of cold-warm, negative-positive, friendly-hostile (recoded), suspicious-trusting, respect-contempt (recoded), disgust-admiration (ingroup, $\alpha=.741$, outgroup, $\alpha=.650$ ).

\section{Results and discussion}

Intergroup bias Intergroup bias was regressed onto British (subgroup) and European (superordinate group) identification. This analysis showed that both subgroup and superordinate identification significantly predicted bias. Subgroup identification was positively related to bias $(\beta=.427, p<.005)$ while superordinate group identification was negatively related to bias $(\beta=-.387, p<.005)$. Entering an interaction term into the multiple regression in the second step revealed no superordinate identification $\times$ subordinate identification interaction $(\beta=-.168$, $p=.706)$.

We also regressed ingroup evaluation onto British and European identification. British identification was positively associated with 
higher ingroup evaluation $(\beta=.445, p<.005)$. In contrast, there was no association between European identification and evaluation of the ingroup ( $\beta=-.194, p=.123)$. We observed no relationship between British identification and outgroup evaluation $(\beta=-.130, p=.320)$. However, European identification was positively associated with outgroup evaluation $(\beta=.359$, $p=.008)$.

The aim of this study was to test our hypotheses using a manipulation of superordinate identity salience that, unequivocally, does not threaten the value of the subgroup identity. The findings of this study replicate those obtained in Study 1. This supports our contention that the effects we observed should be attributed to the distinctiveness threat inherent to our manipulation, rather than any associated value threat.

Having established these effects, we moved on to Study 3 to address the principle aim in this research: to test for a common mediator of the subgroup and superordinate identification effects observed.

\section{Study 3}

In their formulation of the CIIM, Gaertner and colleagues (e.g. Gaertner, Mann, Murrell, \& Dovidio, 1989) argued that the process underpinning reductions in bias following recategorization decreases the distance between the self and former outgroup members. Gaertner et al.'s $(1989,1990)$ studies found that both separate individuals and recategorization representations led to lower bias compared to the control 'two-groups' condition but via different mechanisms. An individualized representation decreased bias because ratings of other ingroup members decreased, whereas there was no change in the ratings of former outgroup members. In the recategorization condition, however, ratings of outgroup members increased while evaluations of other ingroup members remained relatively stable. In line with these findings is the notion that intergroup bias is characterized by pro-ingroup attitudes rather than outgroup derogation (Brewer, 1979).
For example, research has found that prosocial behavior (e.g. Levine, Prosser, Evans, \& Reicher, 2005) and empathy (Hornstein, 1976) are offered more readily to ingroup members than to outgroup members. Therefore, when outgroup members become ingroup members in a common ingroup identity, positive attitudes, behaviors, and cognitions associated with proingroup bias become extended toward former outgroup members (Levine et al., 2005).

Gaertner and Dovidio argued that this specific locus of effect on outgroup evaluations supports the mechanism outlined in their model: that a common ingroup identity brings former outgroup members closer to the self. However, thus far mediational evidence has focused on changes in perceived inter-category structure (i.e. the perception that the intergroup context is defined less by two well-defined subgroups, but more like one overall superordinate category; Gaertner et al., 1990). Little work has, however, directly tested the more specific mediating mechanism outlined by Gaertner and Dovidio-that recategorization improves outgroup evaluations because it brings outgroup members closer to the self: a mediating role of psychological distance between the self and the outgroup. Recently, Dovidio et al. (2004, Study 1) did investigate the issue of merging of the self with an outgroup member via perspectivetaking. They did not find supportive mediational evidence that perspective-taking reduced bias via self-other merging; however, this was not a recategorization context. Related work does, nonetheless, indirectly support the prediction that recognition of common ingroups will decrease bias by decreasing the psychological distance between the self and outgroup. Within the contact literature Wright et al. (1997) provide evidence indicating that extended contact reduces bias via perceived ingroup targetoutgroup target overlap. Specifically, they found that if a perceiver believed there to be closeness between an ingroup member and an outgroup member, the outgroup would become, to a certain extent, included as part of the self. This in turn reduces affective and general prejudice, and increases evaluations of the outgroup. Because 
recategorization is a consequence of contact (and indeed it is this relationship on which the model was built, see Gaertner et al., 1989), this suggests that interventions designed to reduce intergroup bias should do so via decreasing the psychological barrier between the self and outgroup members.

The aim of Studies 3, 4, and 5 was therefore to directly test an idea outlined, but as yet untested: that creating a common ingroup identity leads to a reduction in intergroup bias via decreased psychological distance between the self and the outgroup. However, we take these ideas one step further and argue that it is not only the salience of the superordinate group that will determine bias, and psychological closeness to the outgroup. Rather, it is the relative strength of the subgroup and superordinate identity that will determine bias, via the psychological distance between the self and outgroup. Related work suggests that identification may indeed predict psychological closeness under conditions of differential ingroup-outgroup similarity. A role for identification in determining perceived closeness to the ingroup (vis-a-vis the outgroup) under a distinctiveness threat has been identified by Spears, Doosje, and Ellemers (1997). They found that under conditions of a distinctiveness threat, high ingroup identifiers regarded themselves as being typical members of the ingroup, whereas low identifiers distanced themselves away from the ingroup. On the basis of this previous research we therefore tested the predictions that: (a) with increasing subgroup identification self-to-outgroup similarity would decrease; and (b) with increasing superordinate identification self-to-outgroup similarity would increase. Furthermore, self-to-outgroup closeness would mediate the relationship between both subgroup and superordinate group identification and bias.

\section{Method}

Participants and design Seventy British undergraduate students (35 males, 32 females, ${ }^{5}$ mean age $=20$ ) participated in exchange for a small monetary payment. As in Studies 1 and 2, the British were used as the ingroup, the French as the outgroup, and Europe as the superordinate group.

Procedure The procedure was identical to that of Study 1, with the addition of measures assessing similarity between the self and outgroup. The British and European identification scales were reliable and so were averaged to form single indices ( $\alpha \mathrm{s}=.934$ and .932 respectively).

Dependent measures We used the same evaluative items as used in Study 1. Items for ingroup evaluation and outgroup evaluation were correlated $(r(70)=.450, p<.01$, and $r(70)=.284$, $p<.05$ respectively) so were collapsed to form single indices. As before, intergroup bias was calculated by subtracting outgroup evaluation from ingroup evaluation. Psychological distance between the self and ingroup and outgroup was assessed by asking participants to rate the extent to which they agreed with the following two items; 'I feel similar to British people' and 'I feel similar to French people'. For half of the sample the order of the questions was reversed to ensure counterbalancing.

\section{Results and discussion}

Intergroup bias Preliminary analysis revealed that subgroup (British) and superordinate group (European) identification both significantly predicted bias. British identification was positively related to bias $(\beta=.488, p<.005)$, whereas European identification was negatively associated with bias $(\beta=-.268, p<.05)$. On entering an interaction term into the multiple regression on a second step, there was no superordinate identification $\times$ subordinate identification interaction $(\beta=-.130, p=.664)$.

We further regressed ingroup evaluation onto British and European identification. Again, British identification was associated with ingroup evaluation $(\beta=.463, p<.005)$, whereas there was no association between European identification and evaluation of the ingroup $(\beta=-.002, p=.989)$. As with ingroup evaluation, we also regressed outgroup evaluation onto British and European identification. Here, we observed no relationship between 
British identification and outgroup evaluation $(\beta=-.175, p=.116)$. However, higher European identification was related to higher outgroup evaluation $(\beta=.492, p<.005)$. These findings replicated those of Studies 1 and 2. Our next aim was to see whether similarity to the outgroup mediated these paths.

Path analysis We tested three models using AMOS software (Arbuckle \& Wothke, 1999) and compared their relative fit to ascertain whether our predicted model was the best fit for the data obtained. Model 1, our predicted model, specified that subgroup and superordinate group identification would have an indirect effect on bias via perceived similarity to the outgroup. Our measure of similarity to the outgroup was derived from subtracting ratings of the psychological distance to the ingroup from ratings of psychological distance to the outgroup. We created this index because we were interested in the extent to which participants, in relative terms, felt more similar to the outgroup than the ingroup. Examining similarity to the outgroup alone may not capture the important comparative nature of intergroup perception in this context, in the same way that measuring only outgroup evaluations without reference to ingroup evaluations may be misleading. For example, if both ingroup and outgroup evaluations rise in concert then there is no reduction in intergroup bias, but if only outgroup evaluations are measured we may mistakenly assume that there was. Thus, consistent with our use of a relative measure of outgroup evaluation (i.e. bias, ingroup minus outgroup evaluations) we also used a relative measure of psychological distance to the outgroup (i.e. similarity to outgroup, self-outgroup similarity minus self-ingroup similarity). We also note that while the common ingroup identity model predicts variation only in terms of similarity to the outgroup, this prediction was made only in contexts where identification is not an issue (i.e. a common identity is predicted only to reduce bias). Our contention is that when perceiver identity motivations are involved then this implies a comparative process involving positioning of oneself relative to the ingroup versus the outgroup (e.g. Crisp et al., 2006; Hornsey \& Hogg, 2000a) hence our focus on a relative measure.

This model can be seen in Figure 1. There was a direct relationship between similarity to the outgroup and bias $(\beta=-.64, p<.001)$. The more similar the participants felt to the outgroup (relative to the ingroup), the less biased they were. There was also a significant path between both subgroup and superordinate identification and similarity between self and outgroup. As predicted, however, the nature of the relationship differed. Subgroup (British) identification was negatively correlated with similarity to the outgroup $(\beta=-.56, p<.001)$. In contrast, and as predicted, superordinate identification was positively correlated with relative similarity to the outgroup $(\beta=.35, p<.001)$. In sum then, both subgroup and superordinate identification had indirect effects on bias through relative similarity between self and outgroup. The more participants identified with their subgroup identity, the less similar they perceived themselves to be with the outgroup, and the more biased they were. The more participants identified with their superordinate group, the more similar they felt to the outgroup relative to the ingroup, and the less biased they were.

In order to empirically establish the validity of this model, we next computed two other models and compared fit indices. The fit of the models

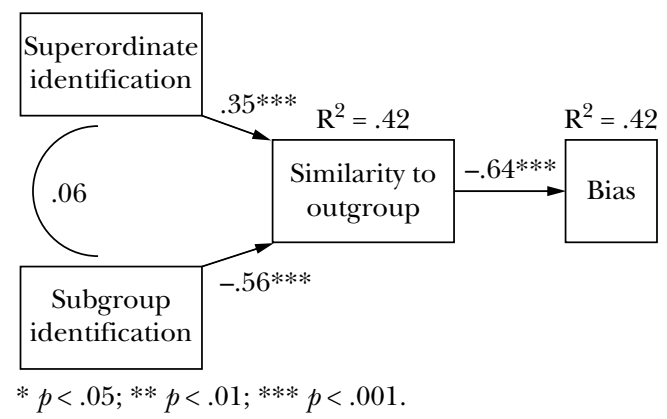

Figure 1. Path analysis model of the relationship between subgroup identification, superordinate group identification, outgroup similarity, and intergroup bias (Study 3). 
tested was assessed by using chi-square, the Comparative Fit Index (CFI) and the Root Mean Square Error of Approximation (RMSEA).

Model 1 (Figure 1) was found to be a good fit: $\chi^{2}=3.44, p=.179, \mathrm{CFI}=.980$, and $\mathrm{RMSEA}=.102$. The first comparison model tested the same paths as outlined in Figure 1, but in addition we tested the direct paths between subgroup and superordinate identification and bias. This model (Model 2) replicated the significant paths observed in Figure 1; however, the additional direct paths tested were nonsignificant. With the inclusion of similarity to the outgroup into the equation there was no longer any direct relationship between subgroup identification and bias $(\beta=.204, p=.08)$, nor between super-ordinate identification and bias $(\beta=.092, p=.368)$.

The second comparison model tested whether similarity to the outgroup best predicted bias (Model 1) or whether bias best predicted similarity to the outgroup (Model 3). In comparison with Model 1, however, Model 3 was a poor fit: $\chi^{2}=16.39, p<.0005, \mathrm{CFI}=.799$, and RMSEA $=.323$.

The findings from Study 3 have qualified the basic relationships observed in Studies 1 and 2 in a number of important ways. First, we replicated the basic relationships observed in Studies 1 and 2-subgroup identification was positively related to post-recategorization bias, but superordinate identification was negatively related to post-recategorization bias. Second, comparison of the different path models supported a mediating role for similarity to the outgroup. The model specifying that subgroup and superordinate group identification had their effects on post-recategorization bias via perceived similarity to the outgroup had a much better fit than either a model specifying the reverse order (bias-similarity) or a model that included direct paths between identification and bias. Importantly, the significant relationships between subgroup and superordinate group identification and bias that were observed in Study 1 and Study 2 became nonsignificant in a model that included similarity to the outgroup as mediator.

In Study 4 we aimed to further test this model, using alternative measures of psychological distance, as well as changing some aspects of the cover story and manipulation to further test the generalizability of the effects. One of the potential criticisms of Study 3 is that our measure of psychological distance between the self and ingroup and items referring to ingroup identification may not have been clearly measuring different constructs (indeed, a factor analysis did not show these items to load on distinct factors). To address this we improved our measure of psychological distance in this study. In particular we created a multi-item scale and explicitly tested whether our ingroup identification and similarity measures were statistically distinct constructs.

Importantly, we also included here both a prerecategorization and post-recategorization measure of bias. This latter addition to our basic design allowed us to test whether the relationship between subgroup and superordinate group identification and bias changes as a function of the cognitive salience of the superordinate categorization. In other words, it provides a control condition against which to compare the effects of identification on bias following recategorization. In Studies 1 to 3 we focused specifically on the processes and outcomes of superordinate and subgroup identification in recategorized contexts. While this is clearly the most targeted focus for understanding what the effects of recategorization might be, it does not tell us whether things are, in fact, different after recategorization than before. In Study 4 we therefore sought to directly test the relationships between identification at different levels of the group hierarchy and bias before and after making a common ingroup identity cognitively salient. We contend that in order for intergroup relations to benefit from high superordinate identification, the relevant common ingroup identity must first be cognitively salient. We thus predicted that the dual and opposing relationships between subgroup and superordinate identification and bias would only operate in common ingroup contexts. Put another way, when only subgroup identities are salient we expect only subgroup identification to predict bias (and for superordinate group identification to exert no moderating effect 
on bias). However, when a common identity is made salient, although we expect subgroup identification to continue to exert its moderating effect, we will then expect superordinate group identification to also predict bias, and indeed, that high superordinate identification will then help to reduce bias associated with high subgroup identification.

\section{Study 4}

\section{Method}

Participants and design Sixty-nine female undergraduates $\left(\right.$ mean age $\left.=19^{6}\right)$ participated in exchange for course credits. As with Studies 1 to 3 , Britain was the ingroup subgroup, France the outgroup subgroup, and Europe the superordinate recategorization.

Procedure To increase generalizability, we used here an alternative cover story. Participants were informed that the study was a wide-scale questionnaire looking at how media coverage can influence emotions, decision-making, and opinions of the general public. Prior to the recategorization manipulation, measures of British $(\alpha=.914)$ and European $(\alpha=.908)$ identification were taken using the scales employed in Studies 1 to 3. Premanipulation measures of bias were administered using the scale employed in Study 2 (ingroup, $\alpha=.711$, outgroup, $\alpha=.660$ ).

Recategorization into a European identity was then introduced by informing participants that:

Europe is currently in a state of political change. Since 1958 the European Union (EU) has been constantly enlarging, and a number of countries have applied to join this ever-growing 'club'. Given that at present, this is an important issue, it is currently receiving extensive media coverage. Please read the following paragraph that recently appeared in a national newspaper.

Participants then read the recategorization manipulation employed in Studies 1 and 3. Following this, participants completed postmanipulation measures of ingroup and outgroup evaluation, again using the General Evaluation
Scale of Wright et al. (1997; ingroup $\alpha=.678$, outgroup $\alpha=.685$ ).

New measures of ingroup and outgroup similarity to self were also used, and included the following items: 'I feel similar to British (French) people in general'; 'I feel that I have a lot in common with British (French) people in general'; and 'I feel that I possess attributes that are associated with British (French) people in general' (ingroup $\alpha=.89$, outgroup $\alpha=.91$ ). Participants then completed a feedback form, were thanked and debriefed.

\section{Results and discussion}

Construct validity The use of multi-item scales to assess all of our key variables, identification, similarity, and evaluation, allowed us here the opportunity to confirm the empirical distinctiveness of these constructs. Nunnally (1967) suggests that when a correlation between two scales is as much as 20 points lower that the average of the within-scale reliabilities of those two scales, the two scales are measuring 'systematic differences in content' (p. 230). Put another way, if between-scale differences outweigh within-scale differences, then the two scales can be considered to be measuring different constructs. We computed this difference for every combination of subgroup identification, ingroup and outgroup similarity, and ingroup and outgroup evaluation. In each case, the correlation between scales was at least 20 points lower than the average of the within-scale reliabilities (ingroup identification vs. ingroup similarity $=.20$; ingroup similarity vs. ingroup evaluation $=.26$; ingroup identification vs. ingroup evaluation $=.38$; ingroup identification vs. outgroup similarity $=.77$; outgroup similarity vs. outgroup evaluation $=.52$; ingroup identification vs. outgroup evaluation $=.69$ ). As such, we concluded that our measures of ingroup identification, similarity to the ingroup and outgroup, and evaluation of the ingroup and outgroup were all distinct constructs.

Change in bias We carried out the same regression analysis as in Studies 1 to 3 but with the added within-subjects factor of time (pre- and 
post-recategorization). Thus, a regression analysis was computed including subgroup, superordinate group identification, and bias at time 1 and time 2 .

Overall, this analysis replicated the findings from Studies 1 to 3 . There was a significant positive relationship between subgroup (British) identification and bias $(\beta=.435, p=.001)$, and a significant negative relationship between superordinate group (European) identification and bias $(\beta=-.285, p=.025)$. Combining pre- and post-bias into a single overall index of bias, without taking account of whether a recategorized superordinate identity was salient or not, therefore yielded effects in line with those we had previously observed. Higher subgroup identification predicted higher bias, higher superordinate identification predicted lower bias.

In order to assess whether identification at subgroup and superordinate levels interacted with time we computed the difference between pre-and post-recategorization bias and regressed this onto the identification indices (this is the same as computing identification $\times$ time interactions in a typical analysis of variance design). In addition to the main effects the subgroup identification $\times$ time interaction was nonsignificant $(\beta=-.032, p=.807)$. This reflected the fact that subgroup identification significantly predicted bias both at time 1 (prerecategorization) $(\beta=.400, p<.01)$, and also at time 2 (post-recategorization) $(\beta=.398$, $p<.01)$. Thus, irrespective of the salience of a superordinate identity, higher subgroup identification predicted higher bias.

There was, however, a significant superordinate identification $\times$ time interaction that qualified the main effect of European identification reported above $(\beta=.267, p<.05)$. This interaction indicated that while superordinate identification did not predict bias prior to making the superordinate (European) identity salient $(\beta=-.160, p=.213)$, after making the superordinate identity salient superordinate identification did predict bias $(\beta=-.356$, $p=.006)$. Finally, on entering an interaction term into the multiple regression on a second step, there was no superordinate identification $\times$ subgroup identification $\times$ time interaction $(\beta=-.042, p=.953)$.

Post-recategorization bias We next carried out an analysis on post-recategorization bias only, which allowed a test of whether we would replicate the basic relationships between identification and bias observed in Studies 1 to 3. Preliminary analysis revealed that subgroup (British) identification was positively correlated with bias $(\beta=.398, p<.01)$, and that superordinate group (European) identification negatively related to bias $(\beta=-.356, p=.006$. $)$ We again regressed ingroup evaluation onto British and European identification. As before, the more respondents identified with their British identity, the higher the evaluation of the ingroup $(\beta=.468, p<.005)$, whereas there was no association between European identification and evaluation of the ingroup $(\beta=-.110$, $p=.374)$. As with ingroup evaluation, we also regressed outgroup evaluation onto British and European identification. British identification was not related to ingroup evaluation $(\beta=-.030$, $p=.814)$, whereas a strong European identity was associated with higher outgroup evaluation $(\beta=.340, p=.01)$.

Path analysis We tested the same three models as in Study 3. Model 1 specifies that both superordinate identification and subgroup identification have their effect on post-recategorization bias indirectly via similarity to the outgroup. This analysis replicated the pattern observed in our previous studies (see Figure 2). We again observed a direct relationship between similarity to the outgroup and bias $(\beta=-.46$, $p<.001)$. Increased perceived similarity to the outgroup was associated with less bias. Subgroup identification was negatively related to perceived self-outgroup similarity $(\beta=-.61, p<.0001)$, while superordinate identification was positively related to perceived self-outgroup similarity $(\beta=.50, p<.0001)$. The model tested in Figure 2 was a good fit: $\chi^{2}=2.28, p=.320$, CFI $=.995$, and RMSEA $=.045$ ).

We again computed two other models and compared fit indices. Model 2 included the direct paths between subgroup and super-ordinate 


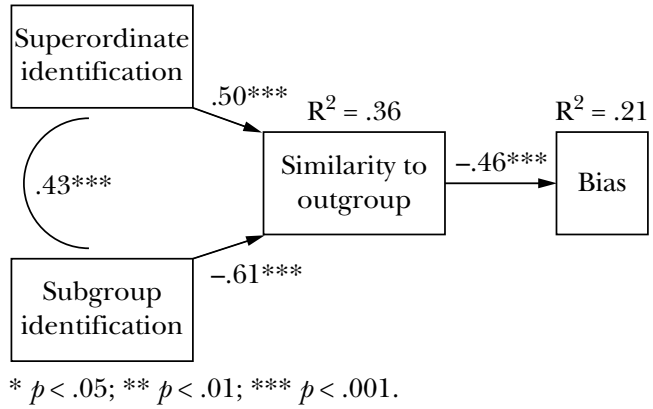

Figure 2. Path analysis model of the relationship between subgroup identification, superordinate group identification, outgroup similarity, and intergroup bias (Study 4).

identification and bias. This model replicated the significant paths seen in Figure 2, however, the additional direct paths tested were nonsignificant. With similarity to the outgroup included, the direct relationships between subgroup identification and bias and between superordinate identification and bias became nonsignificant $(\beta=.188, p=.201$, and, $\beta=-.186$, $p=.180)$.

The second comparison model tested whether similarity to the outgroup best predicted bias (Model 1) or whether bias best predicted similarity to the outgroup (Model 3). In comparison with Model 1, however, Model 3 was a poor fit: $\chi^{2}=20.57, p<.0005, \mathrm{CFI}=.673$, and RMSEA $=.370$.

In sum, the findings from Study 4 replicated and extended the basic relationships observed in Studies 1 to 3. Subgroup identification was again positively related to post-recategorization bias, but superordinate identification was negatively related to post-recategorization bias. Comparison of the different path models again supported a mediating role for similarity to the outgroup: the significant relationships between subgroup and superordinate group identification and bias that were observed in Studies 1 and 2 became nonsignificant in a model that included similarity to the outgroup as mediator. Importantly, this study also revealed that subgroup (British) identification was associated with bias regardless of the salience of the superordinate category. On the other hand, there was an interaction between superordinate identification and the salience of the shared European identity. Higher subgroup identification predicted higher intergroup bias irrespective of a salient superordinate identity. In contrast, higher superordinate group identification predicted lower intergroup bias only in contexts where a common ingroup identity was salient. These findings therefore (a) confirm the efficacy of making common ingroup identities salient and (b) qualify this effect: making a common ingroup identity cognitively salient will reduce bias only to the extent that perceivers are committed to, and ascribe meaning to, that common ingroup identity.

\section{Study 5}

In this final study we wanted to confirm the findings from Study 4 using an alternative design and manipulation. Specifically, to strengthen the argument that superordinate identification should only predict similarity and bias when that identity is made salient, we used a betweensubjects design (rather than the within-subjects design used in Study 4). We also again used the minimal manipulation of superordinate category salience employed in Study 2 to provide the most stringent test of this hypothesis.

In this experiment participants completed measures of subgroup and superordinate identification in a control condition and prior to the manipulation of superordinate category salience. One may argue that a salience manipulation should not be necessary for chronic superordinate identifiers, since these individuals should, in theory, consistently and chronically think in terms of their superordinate identity. We argue, however, that while for high subgroup identifiers the evaluative measures themselves make the intergroup context salient (thus subcategories are inherently salient in the judgment context), high superordinate identifiers, in this particular context, will tend to express more positive attitudes to the extent that a superordinate context is salient. This is because here we are dealing with a subgroup that appears to have an ambivalent relationship with its superordinate. British participants may 
in particular be unlikely to think about being European as soon as they think about other member states. Thus while in many cases we might well expect subgroups to immediately think of the superordinate context without explicit prompting, for our British participants it will likely be the case that our manipulation of superordinate category salience will be required to observe the effects we have documented so far.

This experiment also gave us an opportunity to avoid measuring bias twice in a short period of time (as in Study 4). While the finding of different relationships between identification, similarity, and bias as a function of time in Study 4 suggests the repeated measures design was able to tap variability in intergroup evaluations, one could argue this design allowed the possibility that participants guessed the nature of the experiment and adjusted their evaluations to fit in with this. Using a between-subjects design in Study 5 avoids these potential demand characteristics.

\section{Method}

Participants and design Sixty-five female undergraduates (mean age $=22$ ) participated in exchange for a small monetary payment $(£ 1)$. As with studies 1 to 4 , Britain was the ingroup subgroup, France the outgroup subgroup, and Europe the superordinate recategorization.

Procedure The procedure was the same as in Study 2 except that here half the participants were assigned to a control condition in which they simply completed the identification, similarity, and evaluation measures, while half completed the identification measures, then a manipulation of superordinate category salience, and finally the similarity and evaluation measures. Participants were presented with a list of continents, and were simply asked to identify from which they came: Africa, Antarctica, Asia, Europe, Oceania, North America, or South America. Measures of British $(\alpha=.887)$ and European $(\alpha=.945)$ identification were taken using the scales employed in Studies 1 to 4 .

Following the identification measures, and in the experimental condition, the manipulation of superordinate category salience, measures of ingroup and outgroup similarity to self were as used in Study 4 and were completed by participants (ingroup $\alpha=.900$, outgroup $\alpha=.914$ ), then the measures of ingroup and outgroup evaluation, again using the General Evaluation Scale of Wright et al. (1997; ingroup $\alpha=.597$, outgroup $\alpha=.640$ ). Here, in contrast to Studies 3 and 4, participants completed the similarity measures before the evaluative measures. Finally, participants completed a feedback form, were thanked and debriefed.

\section{Results and discussion}

Construct validity We again used the Nunnally (1967) test to confirm the empirical distinctiveness of the constructs tested. We computed this difference for every combination of subgroup identification, ingroup and outgroup similarity, and ingroup and outgroup evaluation. In every case the correlation between scales was 20 points lower than the average of the withinscale reliabilities (ingroup similarity vs. ingroup evaluation $=.39$; ingroup identification vs. ingroup evaluation $=.49$; ingroup identification vs. outgroup similarity $=.71$; outgroup similarity vs. outgroup evaluation $=.53$; ingroup identification vs. outgroup evaluation $=.55$ ) except one, where nonetheless the difference approached .20: ingroup identification vs. ingroup similarity $=.17$. As such, we concluded that our measures of ingroup identification, similarity to the ingroup and outgroup, and evaluation of the ingroup and outgroup, were all distinct constructs.

Similarity Because participants in this study completed the similarity measures prior to the evaluation measures we report them here first. A moderated regression analysis was computed including categorization conditions, subgroup identification, and superordinate group identification as predictor variables, and similarity to the outgroup (similarity to outgroup minus similarity to ingroup) as the dependent variable.

Overall, there was a significant negative relationship between subgroup (British) identification and similarity to the outgroup 
$(\beta=-.562, p<.0005)$, and a significant positive relationship between superordinate group (European) identification and similarity to the outgroup $(\beta=.409, p<.0005)$. Thus, without taking account of whether a recategorized superordinate identity was salient or not, higher subgroup identification predicted more differentiation from the outgroup (less similarity to the outgroup), while higher superordinate identification predicted higher perceptions of similarity with the outgroup.

In addition to these main effects there was one further effect, the predicted superordinate group identification $\times$ categorization condition interaction $(\beta=.675, p=.038)$. This interaction indicated that while superordinate identification did not predict similarity to the outgroup prior to making the superordinate (European) identity salient $(\beta=.214, p=.228)$, after making the superordinate identity salient superordinate identification did predict similarity to the outgroup $(\beta=.587, p<.0005)$. The absence of a subgroup identification $\times$ categorization condition interaction $(\beta=-.092, p=.816)$ indicates that subgroup identification significantly predicted similarity to the outgroup both in the control condition $(\beta=-.547, p=.004)$, and also in the recategorization condition $(\beta=-.478, p=.001)$. Thus, irrespective of the salience of a superordinate identity, higher subgroup identification predicted lower similarity to the outgroup.

Bias Overall, there was a significant positive relationship between subgroup (British) identification and bias $(\beta=.461, p<.0005)$, and a significant negative relationship between superordinate group (European) identification and bias $(\beta=-.238, p=.047)$. Thus, without taking account of whether a recategorized superordinate identity was salient, higher subgroup identification predicted more bias, while higher superordinate identification predicted less bias. There were no other significant effects; the predicted superordinate group identification $\times$ categorization condition interaction was not significant $(\beta=-.380, p=.292)$. However, examination of the relationship between identification and bias in the control and recategorization conditions separately revealed a pattern consistent with that observed for similarity to the outgroup, and that observed in Study 4. While superordinate identification did not predict bias prior to making the superordinate (European) identity salient $(\beta=-.132, p=.476)$, after making the superordinate identity salient superordinate identification did predict bias $(\beta=-.399, p=.018)$. Furthermore subgroup identification significantly predicted bias both in the control condition $(\beta=.456, p=.019)$, and also in the recategorization condition $(\beta=.423$, $p=.013)$. So, irrespective of the salience of a superordinate identity, higher subgroup identification predicted higher bias.

Path analysis We tested the same three models as in our previous studies. Model 1 specifies that both superordinate identification and subgroup identification have their effect on postrecategorization bias indirectly via similarity to the outgroup. This analysis replicated the pattern observed in our previous studies (see Figure 3). We again observed a direct relationship between similarity to the outgroup and bias $(\beta=-.57$, $p<.001)$. Increased perceived similarity to the outgroup was associated with less bias. Subgroup identification was negatively related to perceived self-outgroup similarity $(\beta=-.56, p<.0001)$, while superordinate identification was positively related to perceived self-outgroup similarity $(\beta=.41, p<.0001)$. The model tested in Figure 3 was a good fit: $\chi^{2}=3.40, p=.183$, CFI $=.973$, and RMSEA $=.109$.

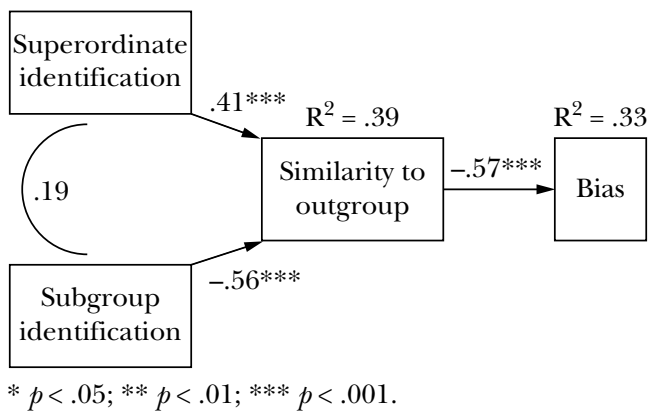

Figure 3. Path analysis model of the relationship between subgroup identification, superordinate group identification, outgroup similarity, and intergroup bias (Study 5). 
We again computed two other models and compared fit indices. Model 2 included the direct paths between subgroup and superordinate identification and bias. This model replicated the significant paths seen in Figure 3, however, the additional direct paths tested were nonsignificant. With similarity to the outgroup included, the direct relationships between subgroup identification and bias approached significance $(\beta=.238 p=.065)$, and the relationship between superordinate identification and bias was nonsignificant $(\beta=-.053, p=.657)$.

The second comparison model tested whether similarity to the outgroup best predicted bias (Model 1) or whether bias best predicted similarity to the outgroup (Model 3). In comparison with Model 1, however, Model 3 was a poor fit: $\chi^{2}=16.08, p<.0005, \mathrm{CFI}=.731$, and RMSEA = .345. In sum, the findings from Study 5 replicated and extended the basic relationships observed in Studies 1 to 4 using a betweensubjects design. Only when a superordinate common ingroup identity was salient did identification with this superordinate group lead to greater perceived similarity to the outgroup, and less intergroup bias. These findings support the idea that not only the salience of a common ingroup identity, but identification with that identity, is important for achieving maximally effective reductions in intergroup bias.

\section{General discussion}

The aim of this research was to extend work on Gaertner and Dovidio's (2000; Gaertner et al., 1993) Common Ingroup Identity Model to examine whether both subgroup and superordinate group identification predicted attitudes toward the outgroup. These questions were examined in the context of a naturally occurring hierarchy, British and European identity. In Studies 1 to 5 we found that higher British (subgroup) identification was associated with higher bias toward to the outgroup, while higher European identification was associated with lower levels of bias toward the outgroup. In addition Studies 3, 4, and 5 yielded evidence that the psychological distance between the self and outgroup mediated the positive relationship between subgroup identification and bias, and the negative relationship between superordinate identification and bias. Below we discuss the theoretical and practical implications of these findings.

\section{Theoretical implications}

The social categorization approach has provided a framework which has been used as a basis for the development of a variety of bias-reduction techniques. Central to this strategy is the notion that the cognitive-perceptual processes which facilitate discrimination (i.e. salience of intergroup boundaries) can also provide the solution. The CIIM involves shifting intergroup boundaries to include outgroup members within a new ingroup, leading to reduced intergroup bias. Our findings extend this research by examining the effects of multiple commitments at multiple levels of inclusiveness.

Previously it has been observed that merging an ingroup with an outgroup can be used effectively within minimal groups (e.g. Gaertner et al., 1989), but not so effectively within some natural groups (Hornsey \& Hogg, 2000a). This led to the assumption, drawing also on Jetten's work concerning reduced intergroup distinctiveness (e.g. Jetten \& Spears, 2003), that commitment to the ingroup would moderate the effectiveness of attempts to recategorize ingroup and outgroup into a common ingroup identity. Recent evidence suggests that the ability of this technique to promote outgroup liking is most effective for low ingroup identifiers, given their comparative willingness to drop the ingroup categorization when it seems to no longer be a meaningful way to define oneself. In contrast, high ingroup identifiers are the most compelled to protect the group image (e.g. Spears et al., 1997). Thus, perceived threat to the continuation of the initial ingroup identity via recategorization would lead to, at best, no effect on bias, or, at worst, an increase in intergroup bias (Crisp \& Beck, 2005; Crisp et al., 2006; Hornsey \& Hogg, 2000a; Roccas \& Schwartz, 1993; van Leeuwen et al., 2003). One could argue that recategorization contexts represent little 
more than alternative means of manipulating intergroup similarity, something that has been examined in the social identity literature with respect to subgroup identification for some time. There is, however, something quite unique about recategorization contexts that differentiates the type of work reported here from extant work in the social identity domain, and that is that recategorization contexts generally include a superordinate category. As such, there are two layers of identification to examine-not only the predictive value of subgroup identification, but also of superordinate group identification. The latter provides something of a unique context for social identity research, but also has some highly important implications for work on the common ingroup identity model.

One of the key findings of our studies is that although high subgroup identification has a negative impact on intergroup relations following recategorization, superordinate identification has a positive impact. These findings fall nicely in line with research from the immigration/ acculturation literature, which similarly assert that dual identification is a potentially beneficial strategy for the encouragement of harmonious intergroup attitudes in multicultural societies. Like Huo et al. (1996), we found that high identification with a subgroup is not necessarily always a barrier to positive intergroup attitudes. Rather, if there is simultaneous attachment to a superordinate group, the potentially negative effects of subgroup identification can be regulated by the counteractive effects of commitment to the inclusive group (see also Bizman \& Yinon, 2001).

Interestingly, in all the studies subgroup identification was related to ingroup evaluation, but unrelated to outgroup evaluation. Conversely, superordinate identification was related to outgroup evaluation but not to ingroup evaluation. This seems to suggest a further insight into the evaluative mechanisms by which recategorization reduces intergroup bias. When successful in its purpose, a common ingroup identity reduces bias by boosting evaluations of the outgroup (Gaertner et al., 1989; see also Brewer, 1979). The current data indicate that outgroup evaluation in these circumstances is heightened only really for those with an emotional attachment to the overarching category, whereas this is not the case for those with strong affective ties to the ingroup. Furthermore, our findings with respect to the psychological distance between the self and outgroup (relative to the ingroup) offer, to our knowledge, the first direct support for Gaertner and colleagues' assertion that recategorization decreases self-outgroup psychological distance, and that this is responsible for reductions in bias. The findings illustrate that psychological distance to the outgroup is higher for high superordinate group identifiers and lower for high subgroup identifiers: the more committed perceivers are to their superordinate group, the more they embrace the outgroup within this common ingroup identity.

In sum, taking into account the relationships between subgroup/superordinate group identification and ingroup/outgroup evaluations, and the role of self-outgroup psychological distance, the data provide strong support for the notion that: (a) recategorization alone would not be sufficient for the successful attenuation of social conflict; and (b) the utility of common ingroup identities as potential interventions would be inhibited by a strong subgroup identity, but facilitated by the development of a superordinate identity. Some practical implications of these findings are discussed below.

\section{Pragmatic implications}

This research is not only important from a direct conflict management perspective. Situations in which subgroup identities are nested within more inclusive superordinate groups are widespread. We focused our investigation within the context of national and supranational identities although multiracial groups within education, cultural-ethnic groups within nations, and intraorganizational contexts provide other examples. In this case, developing commitment to a shared European identity within the context of European integration may harness less xenophobic attitudes toward individuals of 
various member states. This would have a positive influence on intergroup attitudes even where patriotism is high, and concerns are directed toward perceived European integration in combination with the loss of national sovereignty. Commitment to common ingroup identities may be able to act as a buffer in times of identity change, especially when group members are faced with the potential dissolution of intercategory boundaries.

However, a further potential caveat is worth mentioning here in order to provide a more comprehensive account of the applicability of superordinate identification to various intergroup contexts. Our analysis so far has focused on subgroups which are similar in status, and the implications of these data might not hold so well to situations where sociostructural asymmetries characterize the nature of intergroup relations. For instance, Arends-Toth and van de Vijver (2003) found that although dual identification has positive consequences for intergroup relations from the perspective of ethnic minorities, majority samples do not hold such favorable attitudes toward dual identification. Instead, they prefer ethnic groups to relinquish their cultural attachments and instead, assimilate into mainstream society. That majority and minority group members have different perspectives can lead to conflictual relations between the two subgroups, and thus the development of affable relations would be inhibited. Further research would be needed in order to develop a clearer understanding of how positive attitudes between asymmetric subgroups would be best approached.

In conclusion, emerging evidence suggests that motivational factors have a major part to play in triggering and also eradicating intergroup tensions, and thus have important consequences for conflict reduction. When efforts are made to bring together two groups under a common ingroup identity, attachment to the ingroup can have aversive consequences for intergroup relations. However commitment to the newly formed superordinate group can improve intergroup attitudes. This suggests that motivational processes associated with identification have an integral role to play in creating affable intergroup relations, and invite consideration by current and future models of conflict resolution.

\section{Notes}

1. We make a distinction between different types of 'dual identities'. Previous work has tended to regard commitment to a categorization as being the same thing as making a particular categorization salient. We prefer to make the distinction between 'dual identification' and 'simultaneous categorization' respectively. The former refers to actual internalization of, identification with, and affective ties to those social groups (see Bizman \& Yinon, 2001; Huo et al., 1996 for relevant studies). The latter refers to the salience of those group identities (see Hornsey \& Hogg, 2000a; González \& Brown, 2003; for experimental manipulations). It is important for our discussions later in this article that we are dealing with dual identification, i.e. relative identification with subgroups and common ingroup identities, rather than simultaneous categorization (see also van Knippenberg \& van Leeuwen, 2001; Wittig \& Molina, 2000 for similar arguments regarding this distinction).

2. When referring to 'combined effects' we are not referring to an interaction in a statistical sense. Rather, the presence of two main effects will have a 'combined effect'. In other words if both superordinate identification and subgroup identification are high, the presence of the former will cancel out increasing levels of bias implied by the latter.

3. Nine participants did not report their gender.

4. The data were also analyzed using a median split approach, in which these results were replicated and there was no interaction between subgroup identification and superordinate category identification.

5. Three participants did not report their gender.

6. Three participants did not report their age.

\section{Acknowledgements}

This research was funded by a School of Psychology, University of Birmingham doctoral studentship to C. H. Stone. We thank Mein-woei Suen for his help with data collection. 


\section{References}

Arbuckle, J., \& Wothke, W. (1999). AMOS 4 user's reference guide. Chicago: Smallwaters Corporation.

Arends-Toth, J., \& van de Vijver, F. J. R. (2003). Multiculturalism and acculturation: Views of Dutch and Turkish-Dutch. European Journal of Social Psychology, 24, 249-266.

Bizman, A., \& Yinon, Y. (2001). Perceived threat and Israeli Jews' evaluations of Russian immigrants: The moderating role of Jewish and Israeli identity. International Journal of Intercultural Relations, 25, 691-704.

Branscombe, N. R., Wann, D. L., Noel, J. G., \& Coleman, J. (1993). In-group or out-group extremity: Importance of the threatened social identity. Personality and Social Psychology Bulletin, 17, 381-388.

Brewer, M. B. (1979). Ingroup bias in the minimal intergroup situation: A cognitive-motivational analysis. Psychological Bulletin, 86, 307-324.

Brown, R. J., \& Abrams, D. (1986). The effects of intergroup similarity and goal interdependence on intergroup attitudes and task performance. Journal of Experimental Social Psychology, 22, 78-92.

Crisp, R. J., \& Beck, S. R. (2005). Reducing intergroup bias: The moderating role of ingroup identification. Group Processes E Intergroup Relations, 8, 173-185.

Crisp, R. J., Stone, C. H., \& Hall, N. R. (2006). Recategorization and subgroup identification. Predicting and preventing threats from common ingroups. Personality and Social Psychology Bulletin. 32, 230-243.

Crocker, J., \& Luhtanen, R. (1990). Collective selfesteem and ingroup bias. Journal of Personality and Social Psychology, 58, 60-67.

Dovidio, J. F., Gaertner, S. L., Isen, A. M., \& Lowrance, R. (1995). Group representations and intergroup bias: Positive affect, similarity and group size. Personality and Social Psychology Bulletin, 21, 856-865.

Dovidio, J. F., ten Vergert, M., Stewart, T. L., Gaertner, S. L., Johnson, J. D., Esses et al. (2004). Perspective and prejudice: Antecedents and mediating mechanisms. Personality and Social Psychology Bulletin, 30, 1537-1549.

Gaertner, S. L., \& Dovidio, J. F. (2000). Reducing intergroup bias: The common ingroup identity model. Philadelphia, PA: Psychology Press.

Gaertner, S. L., Dovidio, J. F., Anastasio, P. A., Bachman, B. A., \& Rust, M. C. (1993). The common ingroup identity model: Recategorization and the reduction of intergroup bias. In W. Stroebe \& M. Hewstone (Eds.), European review of social psychology (Vol. 2, pp. 247-278). Chichester, UK: Wiley.

Gaertner, S. L., Dovidio, J. F., Rust, M. C., Nier, J., Banker, B. S., Ward, C. M. et al. (1999). Reducing intergroup bias: Elements of intergroup cooperation. Journal of Personality and Social Psychology, 76, 388-402.

Gaertner, S. L., Mann, J. A., Dovidio, J. F., Murrell, A. J., \& Pomare, M. (1990). How does cooperation reduce intergroup bias? Journal of Personality and Social Psychology, 59, 692-704.

Gaertner, S. L., Mann, J. A., Murrell, A. J., \& Dovidio, J. F. (1989). Reducing intergroup bias: The benefits of recategorization. Journal of Personality and Social Psychology, 57, 239-249.

Gaertner, S. L., Rust, M. C., Dovidio, J. F., Bachman, B. A., \& Anastasio, P. A. (1994). The contact hypothesis: The role of a common ingroup identity on reducing intergroup bias. Small Groups Research, 25, 224-249.

González, R., \& Brown, R. J. (2003). Generalization of positive attitude as a function of subgroup and superordinate group identifications in intergroup contact. European Journal of Social Psychology, 33, 195-214.

Hogg, M. A. (2000). Subjective uncertainty reduction through self-categorization: A motivational theory of social identity processes. European Review of Social Psychology, 11, 223-255.

Hogg, M. A. (2001). Self-categorization and subjective uncertainty resolution: Cognitive and motivational facets of social identity and group membership. In J. P. Forgas, K. D. Williams, \& L. Wheeler (Eds.), The social mind: Cognitive and motivational aspects of interpersonal behavior (pp. 323-349). New York: Cambridge University Press.

Hornsey, M.J., \& Hogg, M. A. (2000a). Assimilation and diversity: An integrative model of subgroup relations. Personality and Social Psychology Review, 4, 143-156.

Hornsey, M. J., \& Hogg, M. A. (2000b). Intergroup similarity and subgroup relations: Some implications for assimilation. Personality and Social Psychology Bulletin, 26, 948-958.

Hornsey, M. J., \& Hogg, M. A. (2000c). Subgroup relations: A comparison of mutual intergroup differentiation and common ingroup identity models of prejudice reduction, Personality and Social Psychology Bulletin, 26, 242-256.

Hornstein, H. A. (1976). Cruelty and kindness: A new look at aggression and altruism. Englewood Cliffs, NJ: Prentice Hall. 
Huo, Y. J., Smith, H. J., Tyler, T. R., \& Lind, E. A. (1996). Superordinate identification, subgroup identification, and justice concerns: Is separatism the problem; is assimilation the answer? Psychological Science, 7, 40-45.

Jetten, J., Branscombe, N. R., Spears, R., \& McKimmie, B. M. (2003). Predicting the paths of peripherals: The interaction of identification and future possibilities. Personality and Social Psychology Bulletin, 29, 130-140.

Jetten, J., \& Spears, R. (2003). The divisive potential of differences and similarities: The role of intergroup distinctiveness in intergroup differentiation. European Review of Social Psychology, 14, 203-241.

Jetten, J., Spears, R, \& Manstead, A. S. R. (1996). Intergroup norms and intergroup discrimination: Distinctive self-categorization and social identity effects. Journal of Personality and Social Psychology, 71, 1222-1233.

Jetten, J., Spears, R., \& Manstead, A. S. R. (2001). Similarity as a source of differentiation: The role of group identification. European Journal of Social Psychology, 31, 621-640.

Jetten, J., Spears, R., \& Postmes, T. (2004). Intergroup distinctiveness and differentiation: A meta-analytic integration. Journal of Personality and Social Psychology, 86, 862-879.

Levine, M., Prosser, A., Evans, D., \& Reicher, S. (2005). Identity and emergency intervention: How social group membership and inclusiveness of group boundaries shape helping behavior. Personality and Social Psychology Bulletin, 31, 443-453.

Lipponen, J., Helkama, K., \& Juslin, M. (2003). Subgroup identification, superordinate identification and intergroup bias between the subgroups. Group Processes $\mathcal{E}$ Intergroup Relations, 6, 239-250.

Luhtanen, R., \& Crocker, J. (1992). A collective self-esteem scale: Self-evaluation of one's social identity. Personality and Social Psychology Bulletin, $18,302-318$.

Medrano, J. D. (2003). Framing Europe: Attitudes to European integration in Spain, Germany and the United Kingdom. Princeton, NJ: Princeton University Press.

Mlicki, P. P., \& Ellemers, N. (1996). Being different or being better? National stereotypes and identifications of Polish and Dutch students. European Journal of Social Psychology, 26, 97-114.

Nunnally, J. C. (1967). Psychometric theory. New York: McGraw-Hill.
Oakes, P. J. (1987). The salience of social categories. In J. C. Turner, M. A. Hogg, P. J. Oakes, S. D. Reicher, \& M. S. Wetherell (Eds.), Rediscovering the social group: A selfcategorization theory (pp. 117-141). Oxford, UK: Blackwell.

Roccas, S., \& Schwartz, S. H. (1993). Effects of intergroup similarity on intergroup relations. European Journal of Social Psychology, 23, 581-595.

Rutland, A., \& Cinnirella, M. (2000). Context effects on Scottish national and European self-categorization: The importance of category accessibility, fragility and relations. British Journal of Social Psychology, 39, 495-519.

Spears, R., Doosje, B., \& Ellemers, N. (1997). Self-stereotyping in the face of threats to group status and distinctiveness: The role of group identification. Personality and Social Psychology Bulletin, 23, 538-553.

Spears, R., Jetten, J., \& Scheepers, D. (2002). Distinctiveness threat and the definition of collective self: A tripartite model. In A. Tesser, J.V. Wood, \& D.A. Stapel (Eds.), Self and motivation: Emerging psychological perspectives (pp. 147-171). Washington, DC: American Psychological Association.

Tajfel, H. (1982). Social psychology of intergroup relations. Annual Review of Psychology, 33, 1-39.

Tajfel, H., \& Turner, J. C. (1986). The social identity theory of intergroup behavior. In S. Worchel \& W.G. Austin (Eds.), Psychology of intergroup relations (2nd ed). Chicago: Nelson-Hall.

Turner, J. C., Brown, R. J., \& Tajfel, H. (1979). Social comparison and group interest in ingroup favoritism. European Journal of Social Psychology, 9, 187-204.

Turner, J. C., Hogg, M. A., Oakes, P. J., Reicher, S. D., $\&$ Wetherell, M. S. (1987). Rediscovering the social group: A self-categorization theory. Oxford, UK: Basil Blackwell.

van Knippenberg, D., \& van Leeuwen, E. (2001). Organizational identity after a merger: Sense of continuity as the key to postmerger identification. In M. A. Hogg \& D. J. Terry (Eds.), Social identity processes in organizational contexts (pp. 249-264). Philadelphia: Psychology Press.

van Leeuwen, E., van Knippenberg, D., \& Ellemers, N. (2003). Continuing and changing group identities: The effects of merging on social identification and ingroup bias. Personality and Social Psychology, 29, 679-690. 
Wittig, M. A., \& Molina, L. (2000). Moderators and mediators of prejudice reduction. In S. Oskamp (Ed.), Reducing prejudice and discrimination (pp. 295-318). Mahwah, NJ: Erlbaum.

Wright, S. C., Aron, A., McLaughlin-Volpe, T., \& Ropp, S. A. (1997). The extended contact effect: Knowledge of cross-group friendships and prejudice. Journal of Personality and Social Psychology, 73, 73-90.

Paper received 13 December 2005; revised version accepted 19 March 2007.

\section{Biographical notes}

CATRIONA STONE is a teaching fellow at the University of Exeter. Her research interests are primarily in intergroup relations and conflict reduction.
RICHARD CRISP is Professor of Psychology in the Centre for the Study of Group Processes at the University of Kent. He did his BA in Experimental Psychology at the University of Oxford and his PhD at Cardiff University. His research interests focus on the psychology of prejudice, social cognition and intergroup relations. 